\title{
Logística reversa: um estudo sobre os brechós de uma cidade do interior de São Paulo
}

Reverse logistics: a study on the thrift store of a city of the interior of São Paulo

Logística reversa: un estudio sobre los brechos de una ciudad del interior de São Paulo

\author{
Aline Silva Fernandes \\ Graduada em Administração, UNOESTE, Brasil. \\ asfernandes.adm@gmail.com \\ Lechan Colares-Santos \\ Professor Mestre, UNOESTE, Brasil. \\ lechan@unoeste.br
}

Álvaro Costa Jardim Neto Professor Mestre, UNOESTE, Brasil. alvaro@unoeste.br. 


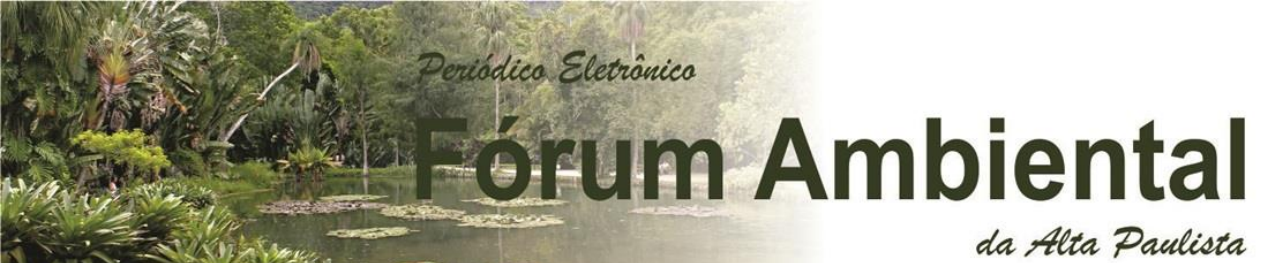

Volume 14, Número 5, 2018

ISSN 1980-0827

\section{RESUMO}

O consumismo dos últimos anos repercutiu negativamente nos setores econômico, social e principalmente ambiental, esse último, por vezes irreversível, devido a essas questões houve uma mudança cultural nas gerações contemporâneas que passaram a observar os impactos causados por esse comportamento. Essa mudança proporcionou ao mercado especializado na venda de artigos usados uma considerável expansão e dentro desse mercado os brechós tiveram um crescimento significativo. Diante disso, este estudo se justifica por investigar o canal reverso em que os brechós estão inseridos, mais especificamente, a logística reversa de reuso de vestuário em uma cidade do interior do Estado de São Paulo. Portanto esse artigo buscou identificar as dificuldades encontradas pelos brechós em repor seus estoques para atender à crescente demanda. Este estudo foi realizado por meio de pesquisa bibliográfica e métodos empíricos realizados por meio de entrevistas com empreendedores da área. Foi constatado que a maior dificuldade está na fase de suprimentos, pois de forma geral a população ainda não adquiriu o habito de descartar o vestuário usado de forma a suprir esse mercado.

PALAVRAS CHAVE: Logística Reversa. Mudança Cultural. Sustentabilidade. Brechós.

\section{ABSTRACT}

The consumerism of recent years has had a negative impact on the economic, social and especially the environmental sectors, the latter, sometimes irreversible, because of these issues there was a cultural change in the contemporary generations that began to observe the impacts caused by this behavior. This change gave the market specialized in the sale of used articles a considerable expansion and within that market the thrift stores had a significant growth. In view of this, this study is justified by investigating the reverse channel in which the thrift stores are inserted, more specifically, the reverse logistics of clothing reuse in a city in the interior of the State of São Paulo. Therefore, this article sought to identify the difficulties encountered by thrift stores in replenishing their inventories to meet growing demand. This study was carried out through bibliographical research and empirical methods performed through interviews with entrepreneurs in the area. It was found that the greatest difficulty is in the supply phase, since in general the population has not yet acquired the habit of discarding used clothing in order to supply this market.

KEY WORDS: Reverse Logistics. Cultural Change. Sustainability. Thirft store.

\section{RESUMEN}

El consumismo de los últimos años repercutió negativamente en los sectores económico, social y principalmente ambiental, ese último, a veces irreversible, debido a esas cuestiones hubo un cambio cultural en las generaciones contemporáneas que pasaron a observar los impactos causados por ese comportamiento. Este cambio proporcionó al mercado especializado en la venta de artículos usados una considerable expansión y dentro de ese mercado los brechós tuvieron un crecimiento significativo. Por este motivo, este estudio se justifica por investigar el canal reverso en que los brechós están insertados, más específicamente, la logística reversa de reuso de vestuario en una ciudad del interior del Estado de São Paulo. Por lo tanto, este artículo buscó identificar las dificultades encontradas por los brechós en reponer sus existencias para atender a la creciente demanda. Este estudio fue realizado por medio de investigación bibliográfica y métodos empíricos realizados por medio de entrevistas con emprendedores del área. Se constató que la mayor dificultad está en la fase de suministros, pues de forma general la población aún no ha adquirido el hábito de descartar la vestimenta usada para suplir ese mercado.

PALABRAS CLAVE: Logística Reversa. Cambio Cultural. Sostenibilidad. tiendas de segunda mano. 
Introdução

O consumo desenfreado e despretensioso das últimas gerações produziu impactos naturais, sociais e econômicos que atingirão a população por anos vindouros, porém assim como a tecnologia muda rapidamente, o ser humano também evolui e com ele seu modo de pensar se transforma. Hoje existem consumidores que além de qualidade se preocupam com a procedência dos produtos que adquirem, com as políticas ambientes da organização e o que vai acontecer a partir do momento do descarte.

Devido a essa mudança cultural o mercado especializado na venda de artigos usados está em expansão, neste segmento os brechós ganham destaque, pois aos poucos o preconceito de comprar roupas usadas está sendo abandonado. Além da questão financeira que inicialmente era o ponto chave desse mercado, existe também a colaboração com o meio ambiente se consideramos que muitas peças estariam destinadas ao lixo e que através dos brechós conseguimos prolongar a vida útil desse tipo de produto. A internet pode ser considerada a mola impulsionadora desse mercado, pois hoje existem sites especializados, blogs, comunidades e grupos que se reúnem para realizar vendas e trocas de artigos usados.

Com o segmento de brechós em expansão veio à preocupação de como suprir a demanda por esse tipo de produto, pois o que antes era destinado à população de classe baixa hoje atinge todas as classes socais. Assim, questiona-se: quais as dificuldades de suprimentos das lojas (brechós) de roupas usadas? Uma vez que essas se encontram em um canal reverso sem coordenação.

Diante disso, este estudo se justifica por investigar o canal reverso em que os brechós estão inseridos na cadeia logística, mais especificamente a logística reversa de reuso de vestuário em uma cidade do interior do Estado de São Paulo. Portanto esse artigo busca identificar as dificuldades encontradas pelos brechós em repor seu estoque para atender à crescente demanda por artigos usados. 


\section{REVISÃO DA LITERATURA}

\section{Sustentabilidade}

Uma das maiores mudanças vividas pela sociedade aconteceu a partir da Revolução Industrial, que proporcionou a maior revolução tecnológica da época, a descoberta da máquina a vapor. Dentro do campo econômico o maior impacto foi o aumento da demanda por mão de obra, que resultou no êxodo rural, trazendo grande parte da população do campo para os grandes centros urbanos para trabalhar em unidades fabris devido ao aumento na produção de diversos bens e serviços. Por sua vez com aumento da produção se fez necessário um maior volume de matéria prima, que em sua maioria vinham das áreas rurais, provocando assim uma mudança do sistema agrário da época.

A Revolução Industrial proporcionou que a sociedade aumentasse sua capacidade de produção, com isso também permitiu uma maior interferência na natureza, devido a maior utilização dos recursos naturais, principalmente dos combustíveis fosseis. Porém, o que queremos destacar nesse artigo não são os indiscutíveis progressos vividos a partir da Revolução Industrial e sim os impactos negativos que vieram paralelamente a ele.

Devido aos impactos naturais evidentes após a Revolução Industrial, foram realizadas a Conferência de Estocolmo para discutir questões sociais, ambientais e econômicas, porém não foi o fim dos questionamentos, se criou então a Comissão Broundtland. A comissão foi autora do relatório "Nosso Futuro Comum" publicado em 1987, contendo conclusões diferentes das sugeridas em Estocolmo e ressaltando o conceito de desenvolvimento sustentável.

De acordo com o relatório Nosso Futuro Comum (1991), a humanidade é capaz de tornar o desenvolvimento sustentável - de garantir que ele atenda às necessidades do presente sem comprometer a capacidade de as gerações futuras atenderem também às suas. $O$ termo sustentabilidade que já era discutido desde a Conferência de Estocolmo tomou uma proporção gigantesca nos dias atuais, seja no âmbito ambiental, econômico, administrativo, educacional, entre outros.

Para entender o que esse termo abrange é necessário saber o que ele significa segundo Terra (2014) "Sustentabilidade s.f. 1. Qualidade do que é sustentável. 2. Econ. Modelo de desenvolvimento que procura observar fatores econômicos, ambientais e sociais de modo a evitar o próprio colapso e a permanecer por tempo indeterminado".

É indiscutível que para o crescimento do país é necessário gerar emprego, renda e movimentar a economia, porém será que é possível que isso aconteça em equilíbrio com o meio ambiente. 
Para que isso aconteça é preciso unir a premissa da sustentabilidade com os ideais de crescimento da sociedade moderna.

Diferentes de outros seres vivos o ser humano não se adapta no ambiente que é inserido, ele transforma o ambiente de maneira que atenda às suas necessidades, sem levar em consideração os impactos que pode causar. No campo empresarial o conceito de sustentabilidade representa uma nova abordagem dos negócios, destaque para o tripé da sustentabilidade, que representa o ambiental, o social e o econômico, conceitos que devem interagir de forma holística.

Segundo Oliveira (2008) com aumento da competição, empresas estão buscando alternativas de melhorar a competitividade através de um melhor desempenho econômico-financeiro. Com isso, passaram a perceber que muitas ações socioambientais, na realidade, não eram custos e podiam ser transformadas em atividades com retorno financeiro ou em oportunidades em novos mercados mais sensíveis a questões socioambientais.

As organizações são as maiores responsáveis pelos impactos ambientes, que resultam em enchentes, deslizamentos, o tão conhecido aquecimento global, todos esses desastres estão ligados diretamente às ações errôneas dos últimos anos. O maior desafio econômico da atualidade é crescer sem que tenhamos que sacrificar ainda mais os recursos naturais.

De acordo com Trigueiro (2005), é perfeitamente possível gerar emprego e renda sem descuidar da variável ambiental, o que significa compatibilizar desenvolvimento com qualidade de vida na sua acepção mais ampla. Isso requer coragem, porque estamos falando de uma nova cultura política, de um novo modelo de gestão e de novos parâmetros para o desenvolvimento.

Em uma sociedade em que a posse de determinados produtos é capaz de classificar pessoas, o consumismo passou a ser uma questão preocupante, pois toda a publicidade em volta nos produtos faz com que se crie uma falsa necessidade fazendo que a aquisição de certos produtos e serviços se torne uma questão de "sobrevivência". O conflito existente entre necessidades e recursos é a essência da teoria econômica, pois nossas necessidades são ilimitadas enquanto os recursos são escassos. Porém, está surgindo uma nova geração preocupada com meio ambiente, que independente do poder aquisitivo da preferência aos fabricantes e comerciantes comprometidos com a política de sustentabilidade e observando também se o consumo de determinado produto ou serviço é fundamental.

Essa mudança cultural originou uma nova economia e as organizações estão preocupadas em associar suas marcas direta e imediatamente à sustentabilidade. As organizações buscam criar 


\section{Periódica Eletránica

estratégias de marketing que enfatizem a sustentabilidade dentro de suas cadeias logísticas, pois entenderam o diferencial competitivo que esse tipo de estratégia pode trazer para si. Os consumidores de todo o mundo estão preocupados e passando a exigir que seus fornecedores reduzam seus impactos sobre o meio ambiente, é visível que os consumidores baseiam cada vez mais seus comportamentos de compra em critérios éticos e ambientais. Outro viés que podemos destacar dentro do conceito de sustentabilidade é a economia verde, as organizações geralmente não entendem e não sabem como se adequar a ela, pois existem pontos obscuros e questionáveis sobre o que é ser uma empresa verde e qual caminho a seguir para atender a esse quesito.

Segundo Makower (2009), um dos maiores problemas que as companhias enfrentam quando começam a criar, executar e comunicar sua estratégia verde é que há pouco acordo sobre o que significa para uma empresa ser vista como verde. É engraçado quando você pensa nisso. Para todos os artigos de jornal, histórias de capa de revista, especiais de televisão, sites, blogs, consultores, conferências, locutores e outros esforços que promovem a noção de empresa ambientalmente responsável, a definição continua dependendo do olho de quem observa.

As organizações buscam estratégias para que os consumidores as vejam como uma empresa sustentável, porém essa questão é altamente complexa, pois independente do que a empresa julga ser correto o consumidor é quem decide se aquilo atende as suas expectativas sociais e ambientais. A sustentabilidade pode ser desenvolvida de diversas formas dentro do âmbito organizacional, porém através da logística reversa as empresas conseguem se adequar mais facilmente a esse novo cenário altamente competitivo.

\section{LOGÍSTICA REVERSA}

Pode-se identificar a logística como o processo de distribuição de bens e serviços desde o fornecimento de matérias-primas até a entrega dos produtos finais ao consumidor. Dentro da logística os canais de distribuição são extremamente importantes, pois são os caminhos escolhidos por uma organização para que seus produtos cheguem até o consumidor final, visando atender o consumidor certo, no local e no momento exato.

Nos últimos anos, com a globalização, a escassez de recursos naturais e as mudanças culturais às organizações passaram a se preocupar com questões que antes eram vistas como mera consequência do consumismo, elas passaram a ver a importância dos canais reversos, seja ele 


\section{Periódica Eletrânica

de pós-venda ou pós-consumo; esse tipo de estratégia quando bem estruturada, eficiente e acreditada passou a ser um grande diferencial competitivo.

Segundo Cavanha Filho (2001) O processo logístico não se encerra na entrega do produto ao cliente, consumidor, mas no caminho completo de reciclagem dos objetos sem valores associados ao produto principal. A sociedade está atenta para as questões do meio ambiente, reutilização e destino de desejos de consumo. Desta forma, a logística reversa é uma estratégia competitiva.

Logística reversa surgiu como uma necessidade para as organizações contemporâneas, porém é um termo muito amplo, onde se podem observar várias premissas como: reciclagem, sustentabilidade, reuso, remanufatura, etc; ideias quais o consumidor está cada vez mais interessado, pois a conscientização sobre os aspectos ligados a reciclagem, reaproveitamento e ao tratamento de resíduos estão sendo cada vez mais valorizados no momento da escolha do produto ou serviço.

As duas categorias da logística reversa, como citado anteriormente, são pós-venda e pósconsumo; entende-se como logística reversa de pós-venda são quando os produtos são reintegrados por algum motivo ao ciclo de negócios, seja por estarem fora da validade, excesso de estoque, estarem em consignação, má qualidade e etc.

Dentro dos canais reversos de pós-consumo existem diferentes formas de processamento e comercialização dos produtos ou de seus materiais constituintes para a reintegração ao ciclo produtivo, classificando-os em condições de uso, fim da vida útil e resíduos industriais, podendo ser enviados a aterros sanitários ou para incineração; outra opção é por meio dos canais de desmanche, reciclagem ou reuso estendendo assim sua vida útil.

Segundo Leite (2003) os canais de distribuição reversos de bens de pós-consumo constituemse nas diversas etapas de comercialização pelas quais fluem os resíduos industriais e os diferentes tipos de bens de utilidade ou seus materiais constituintes, até sua reintegração ao processo produtivo, por meio dos subsistemas de desmanche, reciclagem ou reuso.

Entende-se que a vida útil de um bem se inicia no momento da produção, porém ela não termina quando o mesmo se torna inservível ao proprietário original, pois quando existe a intenção de prolongar a utilização de um bem se busca vias para fazê-lo. Ainda sobre logística reversa podemos observar um crescimento no canal reverso de pós-consumo, principalmente do canal de reuso, podemos compreender esse crescimento devido a questões financeiras, econômicas, ambientais e até pela mudança cultural dos consumidores, que por sua vez deixaram de lado o preconceito de adquirir produtos de segunda mão. 


\section{Periódica Eletránica

Segundo Leite (2003), a logística reversa, por meio de sistemas operacionais diferentes em cada categoria de fluxos reversos, objetiva tornar possível o retorno dos bens ou de seus materiais constituintes ao ciclo produtivo ou de negócios. Agrega valor econômico, ecológico, legal e de localização ao planejar as redes reversas e as respectivas informações e ao operacionalizar ao fluxo desde a coleta dos bens de pós-consumo ou de pós-venda, por meio de processamentos logísticos de consolidação, separação e seleção, até a reintegração ao ciclo.

As vantagens da logística reversa para as organizações são a criação de valor ao marketing do produto, preocupação ambiental como vantagem competitiva e contribuem com a comunidade incentivando a reciclagem. Quando se fala em logística reversa imediatamente remete-se em produtos como embalagens de agrotóxicos, eletrônicos e derivados; pois a existência de leis especificas fazem com que se torne obrigatório o descarte adequado, no entanto, existe outro grande setor do mercado que não conta com esse respaldo, o setor de vestuário.

Fatores como a moda, a mudança das estações, a qualidade das peças faz com que o consumo desse tipo de produto seja maior do que em outros setores do mercado, porém, não existe um canal reverso direto, conhecido e adequado para esse setor.

O maior responsável em absorver parte dos artigos usados do setor de vestuário são os brechós, fazendo o processo de reintegração dos artigos usados ao canal produtivo, sendo comercializados por diversas vezes até o fim da sua vida útil.

Porém não existe um padrão no descarte das peças usadas, apesar de absorverem a maior parte dessas peças os brechós não contam com uma reposição constante de seus estoques, pois ainda não se criou o hábito de levar o excesso vestuário até esse tipo de comercio. Por diversos fatores os consumidores buscam outros meios para o descarte das peças, quando existe algum familiar ou mesmo pessoas conhecidas que não se importam de receber esse tipo de artigo são eles a primeira opção por serem canais mais acessíveis e que não interferem na rotina cotidiana. Outro ponto que pode ser um empecilho para que as peças não sejam levadas até os brechós são as questões sentimentais que os consumidores por vezes adquirem por algumas peças, por exemplo, um vestido de noiva que a mãe guarda para a filha que ainda não tem. 
ISSN $1980-0827$

\section{BRECHÓS}

Ainda discorrendo sobre questões como o consumismo e sustentabilidade, pode-se observar que existe uma mudança cultural nas últimas gerações que foram responsáveis pelo desenvolvimento de uma consciência ambiental que deu origem a um novo nicho de mercado, o segmento especializado em artigos usados, em destaque estão os brechós, como maior responsável em absorver parte desses artigos. Os brechós cresceram à medida que o preconceito com esse tipo de produto diminuiu, evidentemente que o preço é outra questão importante para esse crescimento exponencial.

Antes visto como um sinônimo de mofo, traça e naftalina, hoje o brechó tornou-se uma excelente opção de compra de roupas, bijuterias, bolsas, calçados e acessórios pessoais. 0 brechó dos dias atuais comercializa roupas limpas, bem conservadas, com preços acessíveis, mas ainda existe o preconceito em relação a este tipo de negócio. Compras em brechó possibilitam economia que vai até $80 \%$ em relação às lojas tradicionais (SEBRAE).

Deve-se levar em consideração que a tecnologia e a internet foram os maiores propagadores dessa nova ideia de consumo, existem vários sites, blogs, grupos e comunidades especializadas em venda e troca de artigos usados, esse tipo de comércio aborda desde o vestuário infantil até roupas de luxo.

Outro ponto que ajudou os brechós a se tornarem um negócio conhecido e bastante procurado foi a moda, pois ela vive se reinventando e trazendo de volta peças antigas através de novas releituras e combinações. Os brechós se caracterizam por ser um comercio eclético, com público igualmente diversificado. Diferente do comercio convencional que busca a mercadoria em polos industriais para repor seus estoques, os brechós esperam que a mercadoria chegue até eles, o que pode acontecer de diversas formas, seja por doações, troca ou compra dos mesmos. Observando que quando se trata de doações o lucro é de $100 \%$, porém mesmo quanto o produto é comprado geralmente são preços irrisórios.

Podemos observar também que os brechós têm uma característica peculiar, por não existir uma tabela de preços padrão tendem a formar seus preços de acordo com o ambiente em que estão inseridos e o público que irão atender. Um destaque dentro desse mercado é que praticamente tudo que chega para esses profissionais é aproveitado, pois em sua grande maioria esses profissionais realizam pequenos consertos nas peças recebidas, tornando-as prontas para o reuso. 
PROCEDIMENTOS METODOLÓGICOS

O presente estudo se caracteriza como uma pesquisa exploratória e qualitativa. O objeto de estudo foram os brechós de uma cidade do interior de São Paulo, segundo o órgão regular responsável, existem 18 (dezoito) brechós na cidade, destes, 10 (dez) foram entrevistados, sendo assim, a amostra contemplou $55,5 \%$ do universo, devido a contratempos como a mudança de endereço, o encerramento das atividades e negativa dos empreendedores em responder optou-se por entrevistar aqueles que aceitaram fazer parte da pesquisa. A técnica de coleta de dados utilizada neste estudo foi realizada por meio de entrevista face-a-face. Cada entrevista durou em média cerca de 40 minutos e foram registradas por meio de bloco de notas. A análise dos dados foi feita com base na técnica de análise de conteúdo proposta por Bardin (1977).

\section{ANÁLISE DOS RESULTADOS}

No presente estudo os sujeitos da pesquisa foram os responsáveis pelos brechós, que foram entrevistados e questionados sobre: Quais as principais dificuldades na aquisição das roupas usadas? Como é feita a aquisição, compra, permuta, doação? Quais as principais dificuldades na venda? Qual o perfil do comprador de roupas usadas? Idade, sexo, classe social? Os clientes são sempre os mesmos, ou seja, há uma frequência de compra por parte dos clientes? A loja consegue atender a um perfil específico de clientes de acordo com o tipo de roupa que adquire? Ou seja, é possível segmentar para atender clientes de classes diferentes? O quadro 1 traz a identificação no estudo de cada brechó e o seu respectivo responsável com o qual foi realizado a entrevista. 
QUADRO 1: Identificação dos brechós e responsáveis

\begin{tabular}{|c|c|}
\hline Brechó & Responsável \\
\hline A & 1 \\
\hline B & 2 \\
\hline C & 3 \\
\hline D & 4 \\
\hline E & 5 \\
\hline F & 6 \\
\hline G & 7 \\
\hline H & 8 \\
\hline I & 9 \\
\hline J & 10 \\
\hline
\end{tabular}

Fonte: Elaborado pelos autores

Deste modo, a análise foi realizada com base no quadro 1 para representar os brechós e seus respectivos responsáveis. Quando questionados sobre quais principais dificuldades encontradas na aquisição das roupas usadas os brechós $A, B, C, I$ e J apontaram como causas principais: qualidade das peças e a falta de peças masculinas.

Os brechós E e H a falta de grade (que no mercado de brechós seria a falta de peças iguais de diversos tamanhos) e principalmente o preconceito. Os brechós $D, F$ e $G$ não souberam responder. Quando pedimos para que fossem citados a dificuldades encontradas no momento da venda houve unanimidade, o preço foi apontado como maior dificuldade, segundo o responsável do brechó A "por ser um brechó, as pessoas pensam que ganhamos a mercadoria e por isso teríamos que vender a um preço irrisório".

No momento em que foram questionados sobre o perfil dos clientes o brechó $A$ respondeu que são pessoas geralmente jovens, atentos a moda, porém o brechó I respondeu que são pessoas da comunidade carente, que não tem poder aquisitivo para comprar no comercio convencional; os demais responsáveis não souberam responder.

Outro ponto em que houve concordância nas respostas foi na frequência de compra dos clientes, todos os brechós apontaram que não existe fidelidade da clientela, pois as pessoas que tem o habito de comprar em brechós buscam peças diferentes a cada aquisição por isso estão dispostas a pesquisar em diversas lojas para achar a peça desejada. Por fim, a última questão foi levantada a hipótese de segmentar os clientes desse mercado, apenas o 
responsável pelo brechó $E$ apontou que seria possível fazer essa segmentação, porém que ficaria dependente dos clientes para adquirir um tipo especifico de mercadoria para que assim pudesse realmente direcionar as vendas para um único público. Os demais não souberam responder a esse questionamento.

\section{CONSIDERAÇÕES FINAIS}

Observamos a dificuldade que alguns gestores tiveram para responder os questionamentos da pesquisa, podemos levantar como hipótese a falta de conhecimento de mercado e, sobretudo das técnicas administrativas. $O$ setor de vestuário não conta com um canal reverso específico para o descarte de suas peças, portanto os brechós podem ser considerados os maiores responsáveis pela absorção desse material, por se tratar de um comercio não convencional, os brechós não seguem o mesmo ciclo operacional do varejo habitual, como por exemplo, para a compra de mercadoria não existem o volume certo a ser adquirido ou segmentação da compra de acordo com as estações, também não é possível adquirir a mesma peça em vários tamanhos e não existe uma tabela de preços que se possa seguir.

A mudança cultural dos consumidores expandiu o mercado especializado na venda de artigos e a procura por roupas usadas, porém de qualidade fez com que os brechós passassem a atender não apenas a comunidade carente que os buscava por questões financeiras, mas por outro tipo de público, um consumidor preocupado com o meio ambiente e com o consumismo exagerado. Deste modo, a Logística Reversa apresenta-se como uma ferramenta que tem contribuído positivamente para a sustentabilidade no setor de vestuário, cooperando através da reutilização de peças aumentando assim a sua vida util. A pesquisa demonstrou que os brechós, agregam valor a peças usadas e contribuem com o meio ambiente.

O presente estudo identificou que a maior dificuldade encontrada pelos brechós está fase de suprimentos, pois de forma geral a população ainda não adquiriu o habito de levar descarta as roupas usadas de forma que possam ser aproveitas por esse mercado, particularmente as peças que correspondem ao público masculino são ainda mais difíceis de supridas. No que diz respeito ao perfil do consumidor, não foi possível levantá-lo por meio deste estudo, uma vez que os gestores dos brechós têm pouco conhecimento mercadológico. Desta maneira, sugere pesquisas futuras junto à demanda para identificação do perfil dos consumidores de brechós. 
Para futuros estudos recomendam-se pesquisas para aprofundar o conhecimento sobre a demanda desse mercado; verificar o destino das peças que chegam ao final de sua vida útil e estimar a contribuição desse mercado para a diminuição dos impactos ambientais.

\section{REFERÊNCIAS}

BARDIN, Laurence. Análise de Conteúdo. Edições 70: Brasil, São Paulo, p.38-229, 1977.

CAVANHA FILHO, Armando Oscar. Logística: novos modelos. Rio de Janeiro: Qualitymark, 2001.

LEITE, P. R. Logística reversa: meio ambiente e competitividade. São Paulo: Pearson Prentice Hall, 2003.

OLIVEIRA, J. A. P. Empresas na sociedade: sustentabilidade e responsabilidade social. Rio de Janeiro: Elsevier, 2008.

MAKOWER, Joel. A economia verde: descubra as oportunidades e os desafios de uma nova era dos negócios. São Paulo: Gente, 2009.

NOSSO FUTURO COMUM. Comissão mundial sobre meio ambiente e desenvolvimento. 2 ed, Rio de Janeiro: Fundação Getúlio Vargas, 1991.

TERRA, E. Dicionário da língua portuguesa. 2 ed, São Paulo: Rideel, 2014.

TRIGUEIRO, A.. Mundo sustentável: abrindo espaço na mídia para um planeta em transformação. São Paulo: Globo, 2005. 